\title{
ESTUDIO DE UN BROTE EPIDEMICO DE FIEBRE AMARILLA SELVATICA EN EL PIE DE MONTE DE LA SIERRA NEVADA DE SANTA MARTA. 1979
}

\author{
HERNANDO VIDALES, ${ }^{*}$ BERNARDO BUITRAGO, ${ }^{* \star}$ LUZ HELENA SANIN, ${ }^{\star \star *}$ ALBERTO MORALES, ${ }^{\star \star \star \star}$ \\ HERNANDO GROOT.*****
}

\begin{abstract}
En 1979 se observó en Colombia una epidemia de fiebre amarilla selvática, en las estribaciones más bajas de la Sierra Nevada de Santa Marta, donde nunca antes se había registrado la enfermedad. Los casos ocurrieron en las cercanías de las ciudades de Valledupar y Santa Marta, por entonces infestadas con Aedes aegypti. Veinte de ellos fueron confirmados por examen histopatológico de hígado o por aislamiento de virus y en otros 36 se hizo un diagnóstico de presunción, con base en estudios clínicos, epidemiológicos y serológicos. Entre los primeros hubo 14 defunciones y entre los segundos 13. En las localidades urbanas del área se llevaron a cabo intensas campañas de lucha contra el $A$. aegyptiy de vacunación. No se registraron casos urbanos de la enfermedad.
\end{abstract}

Los enfermos se infectaron en bosques estrechos de galería y en cafetales, donde previa y paralelamente se observó mortalidad en monos ( Alouatta seniculus). El reconocimiento entomológico mostró en la región la presencia de 3 especies de Haemagogus, entre ellas $H$.janthinomys. Con 745 mosquitos se hicieron 192 mezclas para intentar aislamiento de virus, habiéndose obtenido sólo uno positivo para fiebre amarilla, a partir de $H$. janthinomys.

La epidemia descrita es un ejemplo más de la invasión del virus amarílico a nuevos "habitats" rurales, con la consiguiente amenaza para las ciudades vecinas infestadas con $A$. aegypti, por el riesgo de la urbanización del virus, lo cual exige la adopción inmediata de medidas para abatir el mosquito y para vacunar a la población expuesta.

\footnotetext{
* Director

** Jefe de Grupo de Patología

*** Oficina de Epidemiología

*** Jefe Grupo de Entomología

***** Jefe Grupo de Virología
}

Este trabajo se realizó con la coordinación ejecutiva y financiación de la Dirección de Campañas Directas del Ministerio de Salud "SEM" y la estrecha colaboración de la OPS/OMS. 


\section{INTRODUCGION}

Durante los últimos 50 años solo se han descrito en Colombia casos de fiebre amarilla selvática, provenientes en su gran mayoría del pie de monte de los Llanos Orientales, del Magdalena Medio y del Valle del Catatumbo.

En menor proporción se ha comprobado actividad viral también en la región de Urabá, vecina a Panamá y en cercanías de Fonseca, en la parte norte de la vertiente suroriental de la Sierra Nevada de Santa Marta. En Urabá hay apenas el registro de 3 muertes por fiebre amarilla en 1947, las cuales parecen tener relación epidemiológica con la onda que se extendió por Panamá y Centro América entre 1948 y 1958 (1). En Fonseca, en el valle del Río Rancherías, se comprobaron 4 casos humanos de fiebre amarilla y uno en un mono en 1945 (2). Este es el único antecedente de actividad de fiebre amarilla en la región de la Sierra. Ni hacia el sur de la misma vertiente suroriental, ni en la vertiente norte ni en la occidental hay antecedente alguno de la enfermedad, a pesar de que en repetidas ocasiones la zona se ha estudiado con especial cuidado, por razón de la frecuencia con que allí se presentan casos de hepatitis endémica de tipo fulminante. $(3,4)$.

En estas zonas sin historia de fiebre amarilla anterior, se presentó en 1979 un brote de dicha enfermedad, cuya descripción se justifica, no solamente por constituír un ejemplo de la capacidad invasora del virus a zonas nuevas geográficas, sino porque algunos casos se infectaron en ambientes ecológicos un tanto diferentes de los que clásicamente se le reconocen a la enfermedad.

\section{ASPECTOS ECOLOGICOS DE LA SIERRA NEVADA}

La Sierra Nevada de Santa Marta (a la cual nos referimos en lo sucesivo conıo la Sierra), es una pirámide de base triangular, que se levanta aislada en medio de las planicies de la Costa Atlántica de Colombia, a corta distancia del Mar Caribe. Su altura máxima es de 5.700 metros. Su lado norte mira hacia el Caribe y presenta pendientes violentas, que en ocasiones llegan casi verticalmente hasta el propio mar. Los lados sur-este y occidental muestran pendientes suaves y por sus estribaciones descienden numerosos cursos de agua, muchos de los cuales determinan valles estrechos. El occidental mira hacia el valle del Bajo Magdalena y el sur-oriental hacia el valle del Río Cesar, que separa a la Sierra de la Cordillera Oriental.

En líneas generales, la vegetación de la Sierra varía desde aquella vecina a las nieves perpetuas de la cumbre, hasta la tropical de las estribaciones más bajas y del pie de la montaña. En estos últimos lugares hay áreas deforestadas que alternan con bosques, algunos húmedos en las zonas de alta pluviosidad de la vertiente norte y otros, los más, secos, con árboles de mediana talla, en particular hacia el sureste y hacia el occidente.

A alturas superiores a 1.200 metros ha habido alguna deforestación, pero en general predomina el bosque primitivo, que igualmente cubre el interior de la Sierra en las zonas alejadas de las tres vertientes, donde apenas existen, en forma dispersa, algunas tribus de indios kogi y arahuacos.

La población de la Sierra, incluyendo la zona del pie de monte, se calcula en 506.000 habitantes, la mayoría de los cuales se concentra en núcleos urbanos situados en el pie de monte, tales como Santa Marta (245.000), Valledupar (116.000), Ciénaga (110.000) y Fundación (35.000).

Los habitantes restantes, aproximadamente 200.000, se encuentran distribuídos en numerosas aldeas pequeñas ya de las estribaciones, ya del pie de monte, o diseminados, de manera dispersa, por toda la zona rural.

\section{ASPECTOS DE LA ZONA EPIDEMICA}

En las vertientes sureste y oeste, a alturas inferiores a 1.200 metros, la Sierra ha sufrido una tremenda deforestación, como consecuencia de prolongadas actividades de colonización. Hay allí muchas haciendas, dedicadas principalmente a la cría de ganado y, en menor escala, al cultivo de café. Se ven colinas cubiertas por pasto para 
el ganado, cafetales que semejan pequeños bosques, pues la planta se cultiva bajo la sombra, zonas de "rastrojo", correspondientes a bosques secundarios desarrollados en lugares de antiguos cultivos, algunas plantaciones de maíz y de yuca y en la ribera de los ríos y arroyos, estrechos bosques de árboles grandes, a veces constituídos por una sola hilera de ellos en cada banda del río, formando el típico bosque de galería (Fig. 1). En unos pocos lugares, se encuentran además, escasos bosquecillos secos, restos, sin duda, de la vegetación primitiva que cubría el lugar. Fue en este ambiente complejo y heterogéneo, con muy diversos nichos ecológicos, donde la fiebre amarilla hizo su aparición.

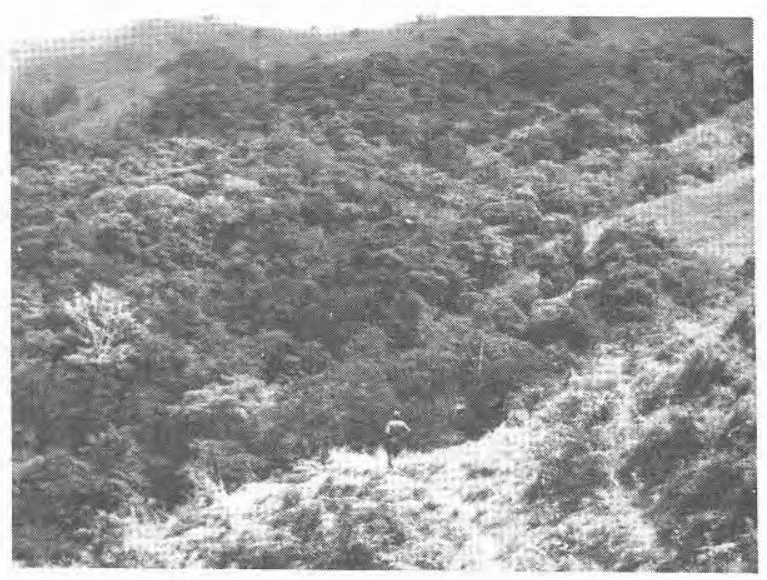

Fig. I. Bosque de galería a lo largo de la quebrada Azúcarbueno.

\section{CURSO DE LA EPIDEMIA}

El primer caso correspondió a un hombre, procedente de la región de Tierra Nueva, a unos 20 kilómetros de Valledupar, quien murió en el hospital de dicha ciudad, el 9 de febrero de 1979. Allí, con base en un estudio histopatológico post-morten de su hígado, se le hizo un diagnóstico claro de fiebre amarilla. En los cuatro meses subsiguientes murieron en el mismo hospital cinco personas provenientes también de la zona rural de Valledupar, que presentaron signos clínicos de fiebre amarilla, pero a quienes no se les hizo diagnóstico de la enfermedad ni se les examinó el hígado histopatológicamente.
De esta situación, así como del fallecimiento de febrero 9, solo se percató el Instituto Nacional de Salud, con sede en Bogotá, cuando se hizo allí el diagnóstico de fiebre amarilla en el hígado de otro individuo, procedente de Río Seco y fallecido en el hospital de Valledupar en julio 28 de 1979. Dos nuevos casos se comprobaron a continuación en el mismo hospital, uno fallecido el 31 de julio y otro, que enfermó en julio 31 , pero que sobrevivió. Hasta esta fecha pues, se habían comprobado 4 casos de la enfermedad en Valledupar. Al mismo tiempo se tuvo noticia de mortalidad de monos en la región, aparentemente iniciada en diciembre de 1978. Esta situación causó verdadero pánico en Valledupar, por estar la ciudad, así como otras localidades urbanas vecinas, altamente infestadas por Aedes aegypti. El índice larvario, por ejemplo, era del $43 \%$ en el propio Valledupar. Las localidades infestadas por el Aedes, estaban pues expuestas al riesgo inminente de serias epidemias de fiebre amarilla en caso de urbanizarse el virus. Si bien, tres de los cuatro casos comprobados arriba señalados habían contraído la enfermedad en regiones rurales sin A aegypti, del caso restante hubo y habrá duda sobre el lugar donde pudo infectarse. En efecto, este individuo (Caso 2 de la Tabla No. 1) residía en un poblado, Río Seco, altamente infestado por Aedes, pero dividía sus actividades diurnas entre el poblado y una finca rural cercana, denominada El Cotoprix (Fig. 2), a 2 kilómetros de distancia, finca en la cual se comprobó la presencia de Haemagogus janthinomys. De todas maneras, el virus estaba activo a corta distancia de lugares altamente infestados por A. aegypti, 5 a 14 kilómetros, o a 2 kilómetros, si este caso hubiera adquirido la infección en El Cotoprix. Por otra parte, había el movimiento natural de pacientes y de personas sanas, o aparentamente sanas, que por una u otra razón fluían de las áreas rurales y silvestres a las localidades urbanas vecinas infestadas por Aedes.

Como consecuencia de esta dramática situación, la División de Campañas Directas del Ministerio de Salud acometió en las zonas urbanas una intensa campaña de vacunación contra la fiebre amarilla y un rápido y enérgico ataque contra el mosquito, 
por medio de Malathion* en volumen ultrabajo y de larvicida Temephos**. Entre agosto 9 y agosto 12 se vacunaron 117.000 personas en Valledupar. La aplicación de insecticidas se inició el 2 de agosto.

TABLA No, 1

CASOS COMPROBADOS DE FIEBRE AMARILLA EN LA SIERRA NEVADA DE SANTA MARTA, COLOMBIA, EN 1.979, POR ORDEN CRONOLOGICO

\begin{tabular}{|c|c|c|c|c|}
\hline CASO Ne & EDAD & $\begin{array}{l}\text { PROCEDENCIA } \\
\text { (MUNICIPIO) }\end{array}$ & $\begin{array}{l}\text { FECHA INICIO } \\
\text { ENFERMEDAD }\end{array}$ & EVOLUCION CLINICA \\
\hline 1 & 30 & Volledupar & Febrero 1 & Muerte en febrero 9 \\
\hline 2 & 25 & Valledupor & Jutio 22 & Muerte en julio 28 \\
\hline 3 & 30 & Volledupar & Julio 21 & Muerte en julio 31 \\
\hline 4 & 8 & Valledupar & Julio 31 & SOBREVIVIO \\
\hline 5 & 29 & Sonta Marta & Julio 31 & Muerte en agosto 10 \\
\hline 6 & 19 & Fundación & Agosto 4 & Muerte en agosto 11 \\
\hline 7 & 27 & Volledupar & Agosto 7 & Muerte en agosto 12 \\
\hline 8 & 27 & Ciénaga & Agosto 7 & Muerte en agosto 15 \\
\hline 9 & 20 & Ciénaga & Agosto 6 & Muerte en agosto 16 \\
\hline 10 & 38 & Sonto Marto & Agosto 15 & Muerte en agosto 23 \\
\hline 11 & 27 & Ciénaga & Agosto 25 & SOBREVIVIO \\
\hline 12 & 15 & Sonte Morta & Agosto 26 & SOBREVIVIO \\
\hline 13 & 18 & Santa Marta & Agosto 26 & SOBREVIVIO \\
\hline 14 & 53 & Valledupar & Agosto 24 & Muerte en agosto 30 \\
\hline 15 & 25 & Santa Marta & ? & Muerte en agosto 30 \\
\hline 16 & 30 & Ciénaga & Agosto 27 & SOBREVIVIO \\
\hline 17 & 23 & Sonta Marta & Agosto 27 & SOBREVIVIO \\
\hline 18 & 45 & Ciénaga & Octubre 9 & Muerte en octubre 26 \\
\hline 19 & 31 & Ciénaga & Octubre 25 & Muerte en octubre 30 \\
\hline 20 & 20 & Ciénaga & Noviembre 3 & Muerte en noviembre 5 \\
\hline
\end{tabular}

* En oños; todos vorones

La comprobación de casos de fiebre amarilla en las cercanías de Valledupar tenía importancia especial, pues como nunca antes se había encontrado allí la enfermedad selvática, los monos de la región bastante numerosos por cierto, eran susceptibles al

* dimetil fósforoditioato de dietil mercaptosuccinato. ** tetrametil thiodi p-fenilen fósforotioato,

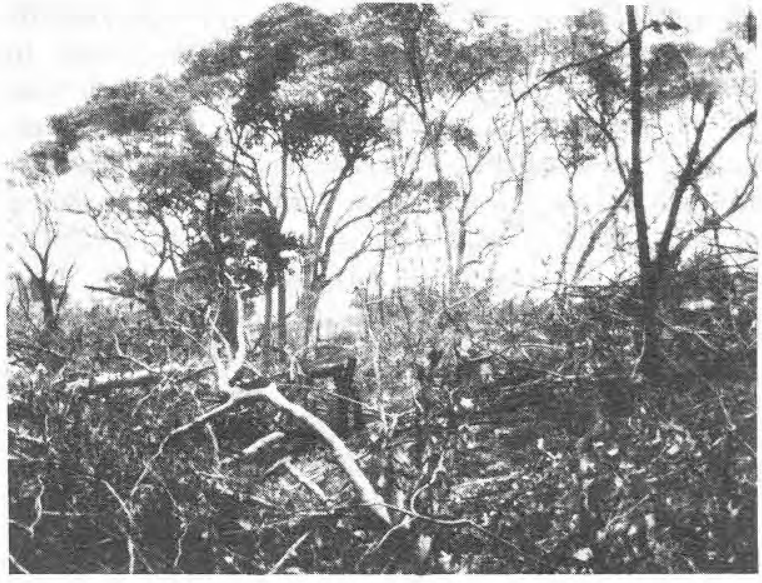

Fig. 2. Desmonte en medio de un raquitico bosque seco tropical en la finca El Cotoprix.

virus y ofrecían así un magnífico medio para su diseminación por toda la región de la Sierra. Por esta razón, el diagnosticarse el segundo caso en los primeros días de agosto, se pronosticó que la enfermedad habría de presentarse en otros lugares de la Sierra en las semanas y meses subsiguientes. En efecto, así ocurrió pero con rapidez mayor que la esperada, pues en agosto 10 murió un enfermo de fiebre amarilla contraída en la vecindad de Santa Marta, en Bonda, a unos 15 kilómetros de ésta; al día siguiente, en agosto 11 falleció otra persona con fiebre amarilla, adquirida en los bosques vecinos a Fundación (a 80 kilómetros al sur de Santa Marta). Por primera vez en 70 años la fiebre amarilla había llegado al propio Caribe (1) y en dos puertos importantes, Ciénaga y Santa Marta, estaban muriendo pacientes que habían contraído la enfermedad en regiones rurales vecinas. Ambas localidades estaban infestadas por A. aegypti, afortunadamente en baja densidad (3\%); sin embargo, el pánico se extendió por la comarca y al punto se iniciaron medidas de emergencia; vacunación y aplicación de insecticidas en volumen ultrabajo.

\section{CASOS COMPROBADOS}

Además de los cuatro casos iniciales de Valledupar y de los tres de Santa Marta, Fundación y Ciénaga inmediatamente antes relatados, entre agosto 12 y noviembre 5 se 
comprobaron 13 casos más de la enfermedad, cinco de los cuales sobrevivieron, nueve buscaron directamente la atención hospitalaria y 4 fueron encontrados en el curso de una pequeña encuesta en las zonas vecinas a Santa Marta durante la cual se identificaron 16 personas febriles.

En conclusión, pues, se comprobaron 20 casos de fiebre amarilla: 14 fatales (13 por viscerotomía y uno por aislamiento de virus y viscerotomía) y 6 sobrevivientes, por aislamiento de virus. En la Tabla No. 1 se resumen por orden cronológico las procedencias de los 20 casos y en la figura No. 3 se presenta en forma gráfica su distribución por meses. La distribución por edades se presenta en la Figura 4.

FIGURA No. 3

CASOS COMPROBADOS Y SOSPECHOSOS DISTRIBUCION POR MESES

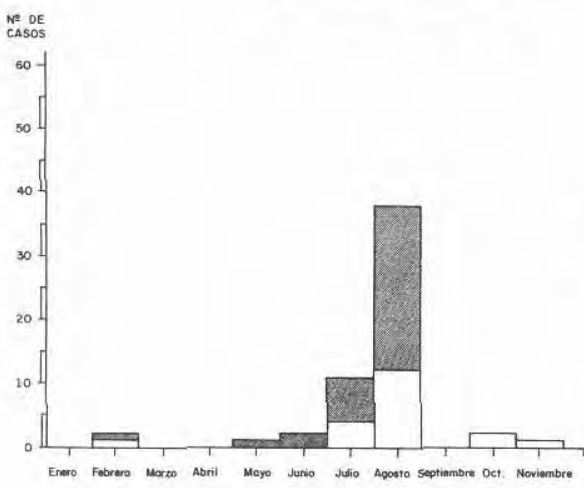

\section{CASOS SOSPECHOSOS}

Fue posible también obtener información sobre otros 36 individuos en quienes se hizo un diagnóstico presuntivo de fiebre amarilla. Estos 36 pacientes sospechosos comprenden 13 muertos y 26 personas que fallecieron en el Hospital de Valledupar entre febrero y julio con síntomas clásicos de fiebre amarilla pero a quienes no se les hizo viscerotomía, tal como se describió arriba; los ocho restantes eran agricultores (dos de ellos aserradores) que según los informes recibidos no habían sido vacunados contra la fiebre amarilla, provenían de zonas frías del país donde no existe la enfermedad, habían
FIGURA NO, 4

\section{CASOS COMPROBADOS}

\section{DISTRIBUCION POR EDADES}

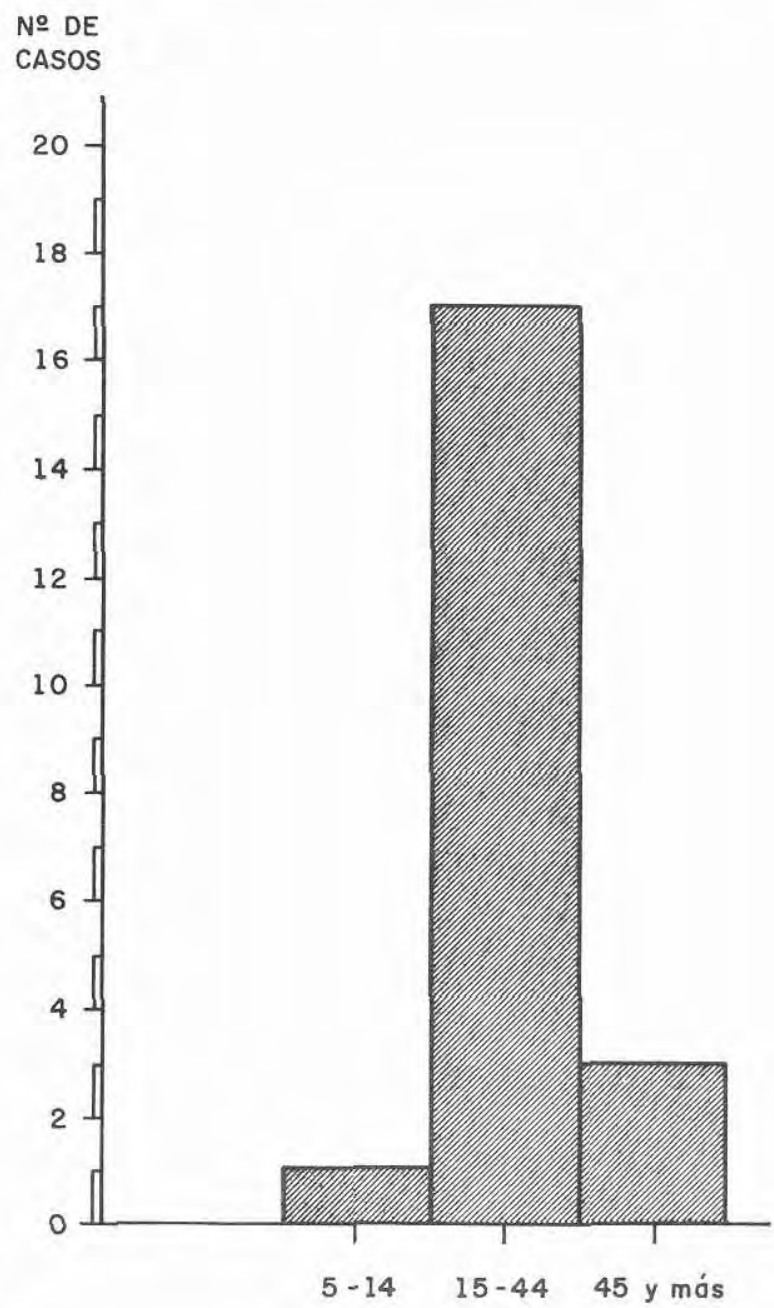

presentado síntomas compatibles con fiebre amarilla y eran compañeros de trabajo de personas en quienes pocos días después se hizo el diagnóstico inequívoco de fiebre amarilla por el laboratorio. A estos ocho muertos tampoco se les hizo estudio histopatológico de hígado.

Los 23 casos considerados como sospechosos y que sobrevivieron, tuvieron todos 
fiebre, vómito y cefalea y en ocasiones ictericia ligera. Correspondían a agricultores sin vacunación antiamarílica en el momento de su episodio febril, a juzgar por las informaciones recibidas, que trabajaban en las mismas zonas donde se comprobaron casos de fiebre amarilla y que enfermaron más o menos simultáneamente con aquellos. Estos pacientes fueron parcialmente estudiados por nosotros durante su convalecencia. Fue posible tomarles muestra de sangre a 9 de ellos, la cual se examinó para fiebre amarilla con los resultados que se indican en la Tabla No. 2. Siete de estos individuos nunca habían recibido vacuna contra la fiebre amarilla y mostraban prueba de neutralización positiva y prueba de HI positiva para antígeno de F.A. a título mayor (aunque no significativamente mayor), que para otros flavivirus; además 4 mostraron anticuerpos CF para antígeno de fiebre amarilla (uno con título 1:4, dos con título 1:8 y uno con título $1: 16)$. Los dos restantes tampoco habían sido vacunados previamente a su episodio febril; lo fueron después de éste, uno 7 días y otro 3 días antes de la toma de sangre. Ambos tenían anticuerpos neutralizantes para fiebre amarilla. En aquella persona vacunada siete días antes de la toma de sangre la interpretación de las reacciones serológicas se ve interferida por dicha vacunación. En aquel individuo vacunado tres días antes, lo mismo que en las 7 personas jamás vacunadas, los datos serológicos, sin ser totalmente indicativos de infección amarílica reciente, no la descartan; muy por el contrario refuerzan el diagnóstico clínico de presunción que se hizo. En efecto

TABLA No. 2

PRUEBAS SEROLOGICAS EN PERSONAS CON ANTECEDENTES CLINICOS COMPATIBLES CON FIEBRE AMARILLA (CASOS SOSPECHOSOS)

\begin{tabular}{|c|c|c|c|c|c|c|c|c|c|c|c|c|c|}
\hline \multirow{2}{*}{ CASO } & \multirow{2}{*}{ EDAD } & \multirow{2}{*}{$\begin{array}{l}\text { VACUNACION } \\
\text { CONTRA F.A. }\end{array}$} & \multirow{2}{*}{$\begin{array}{l}\text { TOMA DE } \\
\text { SANGRE }\end{array}$} & \multirow{2}{*}{$\begin{array}{l}\text { SITUACION } \\
\text { CLINICA }\end{array}$} & \multirow{2}{*}{$\begin{array}{c}\text { PRUEBANT } \\
\text { F.A. }\end{array}$} & \multicolumn{4}{|c|}{ PRUEBAS HI } & \multicolumn{4}{|c|}{ PRUEBAS CF } \\
\hline & & & & & & F.A. & $D_{1}$ & $D_{2}$ & $D_{3}$ & F. A. & $D_{1}$ & $D_{2}$ & $D_{3}$ \\
\hline J.R.L. & 5 & Si, en julio $26 / 81$ & Agosto $2 / 81$ & $\begin{array}{l}\text { Hictericia desde } \\
\text { hace una semana }\end{array}$ & Positiva & $1 / 80$ & $1 / 20$ & $1 / 160$ & $1 / 80$ & $1 / 256$ & $1 / 4$ & $1 / 4$ & $1 / 16$ \\
\hline J.G. & 22 & Si,en agosto $22 / 81$ & Agosto $25 / 81$ & $\begin{array}{l}\text { Fiebre uno sema- } \\
\text { na antes. }\end{array}$ & Positivo & $1 / 160$ & $1 / 40$ & $1 / 40$ & $1 / 20$ & $1 / 8$ & 0 & $1 / 4$ & 0 \\
\hline W.M. & 21 & No & Agosto $28 / 81$ & $\begin{array}{l}\text { Fiebre desde hace } \\
\text { una semana. }\end{array}$ & Positivo & $1 / 40$ & 0 & 0 & 0 & 0 & 0 & 0 & 0 \\
\hline E. Rod. & 18 & No & Agosto 30/81 & $\begin{array}{l}\text { Fiebre desde hace } \\
\text { una semana. }\end{array}$ & Positivo & $1 / 40$ & $1 / 20$ & 0 & $1 / 20$ & $1 / 8$ & 0 & $1 / 4$ & 0 \\
\hline L.J. & 21 & No & Agosto 27/81 & $\begin{array}{l}\text { Fiebre una sema. } \\
\text { na antes. }\end{array}$ & Positiva & $1 / 40$ & 0 & 0 & 0 & 0 & 0 & 0 & 0 \\
\hline F. F & 25 & No & Agosto 23/81 & $\begin{array}{l}\text { Fiebre una sema- } \\
\text { na antes. }\end{array}$ & Positiva & $1 / 40$ & $1 / 20$ & $1 / 20$ & $1 / 20$ & 0 & 0 & 0 & 0 \\
\hline R.A. & 31 & No & Agosto 25/81 & $\begin{array}{l}\text { Fiebre cuatro se- } \\
\text { manas antes. }\end{array}$ & Positiva & $1 / 80$ & $1 / 40$ & $1 / 40$ & $1 / 20$ & $1 / 16$ & 0 & $1 / 8$ & 0 \\
\hline E. Rop & 36 & No & Agosto 25/81 & $\begin{array}{l}\text { Fiebre seis sema- } \\
\text { nas antes. }\end{array}$ & Positiva & $1 / 40$ & $1 / 20$ & $1 / 20$ & $1 / 20$ & $1 / 8$ & 0 & 0 & 0 \\
\hline J. Q. & 23 & No & Agosto 25/81 & $\begin{array}{l}\text { Fiebre seis sema- } \\
\text { nas antes. }\end{array}$ & Positiva & $1 / 40$ & $1 / 20$ & $1 / 20$ & $1 / 20$ & $1 / 4$ & 0 & 0 & 0 \\
\hline
\end{tabular}


resulta difícil creer que la prueba de neutralización no sea el resultado de una infección reciente por el virus de fiebre amarilla, pues los pacientes nunca antes habían estado expuestos al virus.

\section{MAGNITUD DE LA EPIDEMIA}

Nunca se sabrá con precisión cuántos casos de fiebre amarilla se presentaron. Es posible, por ejemplo que haya habido muchos más casos benignos que nunca buscaron atención médica, entre otras razones por corresponder a personas dedicadas al cultivo y al tráfico de la marihuana, actividades ilegales que les hacía rehuír cualquier tipo de autoridad, inclusive la de salud. La búsqueda activa de casos que hicimos, se limitó a pequeñas encuestas realizadas en la región de Valledupar entre el 2 y el 18 de agosto y en Santa Marta entre agosto 22 y septiembre 5 .

En la visita a Santa Marta encontramos en la zona rural 16 personas con síntomas iniciales de una enfermedad febril en quienes fue posible hacer intento de aislamiento de virus. De cuatro de ellos (dos con enfermedad leve que no requirió hospitalización, dos con síntomas moderados), se aisló virus de fiebre amarilla. A tres de estos casos se les hizo reaislamiento con resultado positivo. Aunque el reaislamiento del restante dio resultado negativo, creemos que se trata igualmente de un aislamiento válido por cuanto el suero no se pudo mantener en condiciones satisfactorias de enfriamiento entre el primero y el segundo aislamiento, por desperfectos mecánicos de refrigeración, lo cual explicaría el resultado negativo del reaislamiento. Desafortunadamente por las razones arriba anotadas de renuencia de las personas a colaborar con las autoridades de salud, no fue posible obtener muestras pares de estas 16 personas, así que con excepción de las cuatro mencionadas, en las 12 restantes no hubo manera ni de excluír fiebre amarilla, ni de encontrar modificaciones serológicas que la indicaran. De todas maneras y a pesar de ser la muestra tan pequeña, llama la atención el que de una cuarta parte de individuos con fiebre, se hubiera aislado el virus de la fiebre amarilla.
En resumen, tal como se observa en la Tabla 3, en la epidemia se encontraron 20 casos comprobados y 36 altamente sospechosos de fiebre amarilla, además de los cuales, debió ocurrir un número indeterminado de casos que por ser benignos o por otras razones no buscaron atención médica.

El último caso comprobado de la epidemia fue el de un hombre fallecido en noviembre 5 de 1979. Sin embargo, el virus siguió activo en la región pues en septiembre 15 de 1980 y 10 meses después, se registró otra muerte en un individuo que había adquirido la infección en Guachaca, lugar situado en la vertiente norte de la Sierra, el cual histopatológicamente, se interpretó como fiebre amarilla "tardía".

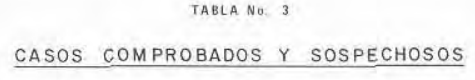

EVOLUCION

\begin{tabular}{|l|c|c|c|c|}
\cline { 2 - 5 } \multicolumn{1}{c|}{} & COMPROBADOS & SOSPECHOSOS & SUB-TOTAL & $\%$ \\
\hline NN DE MUERTOS & 14 & 13 & 27 & 47.3 \\
\hline NN DE SOBREVIVIENTES & 6 & 23 & 29 & 527 \\
\hline TOTALES & 20 & 36 & 50 & 1000 \\
\hline
\end{tabular}

\section{ESTUDIOS HISTOPATOLOGICOS}

En 13 de los 14 casos estudiados se encontró en el hígado el cuadro característico de la fiebre amarilla, con grados variables de necrosis eosinofílica de los hepatocitos formando Cuerpos de Councilman, así como con infiltración variable adiposa y hemorrágica (5). En el ceso restante, un paciente que aparentemente falleció a los 11 días de enfermedad, se encontró un cuadro histopatológico un tanto diferente, tal como se describe a continuación:

Las células parenquimatosas presentan despoblación, más que necrosis, a nivel de las cadenas de la región media del lobulillo, que es solo ocasional en las cadenas 
periportales y pericentrales. En las mismas áreas solo es posible identificar, muy infrecuentemente, Cuerpos de Counçilman. En los espacios así creados por la despoblación mencionada se aprecia notoria proliferación de histiocitos, con linfocitos y ocasionales polinucleares, alternando con numerosos macrófagos que fagocitan un pigmento muy fino, ocre o amarillento, que se tiñe como bilis y no como hemosiderina, constituyendo los Cuerpos de Villela (6), como puede observarse en las figuras $5: \mathrm{a}, \mathrm{b}$ y c. A este nivel, la trama de reticulina, aunque muestra ligera fragmentación, no evidencia colapso ni formación de puentes. Hay además evidencia de regeneración de algunos hepatocitos.

Para esta variedad de fiebre amarilla se ha adoptado el nombre, no completamente adecuado, de forma "tardía", en la cual el enfermo después de sobrevivir a la fase aguda de la enfermedad, muere durante la convalecencia por una infección intercurrente. Nunca sabremos la naturaleza de ésta pues no pudimos obtener una historia clínica completa del paciente ni examinar otras vísceras del mismo. A seis de los casos se les hizo estudio histológico dal riñón, el cual mostró alteraciones de túbulos, tanto en su segmento proximal como distal y en los colectores, consistentes en aplanamiento del epitelio, con picnosis nuclear hasta completa necrosis y desprendimiento hacia la luz tubular en donde los restos epiteliales se mezclan con detritus y cilindros de hemoglobina tal como se observa en la figura 6 . Igualmente se encontraron concreciones calcáreas (Fig. 6, C) y cristales de leucina o isoleucina. No se observó lesión glomerular. (7).

\section{ASPECTOS CLINICOS}

En los 20 casos comprobados, en 16 la enfermedad tuvo un curso clásico, tal como se describe en los libros de texto; dos tuvieron fiebre, cefalea y vómito que hicieron necesaria su hospitalización y que clínicamente se calificaron como moderados; finalmente dos tuvieron apenas fiebre, cefalea y vómito ligeros de solo tres días de duración sin que se requiriera su hospitalización, los cuales se consideraron como casos leves.
Los dos casos leves y los dos moderados se recuperaron. De los 16 casos clásicos catorce correspondían a personas fallecidas; los dos restantes se recuperaron; uno de ellos era un niño de 8 años que recibió al $4^{\circ}$ y al $6^{\circ}$ día de evolución de la enfermedad sendas transfusiones de $250 \mathrm{ml}$ de sangre fresca proveniente de un donante con anticuerpos para fiebre amarilla y se recuperó a partir del $8^{\circ}$ día. Es pues posible que las transfusiones hayan contribuído a su mejoría. Los datos de laboratorio de este niño (Caso No. 4) se muestran en la Tabla No. 4.

TABLA No. 4

DETALLE DE AISLAMIENTO DE VIRUS

Y PRUEBAS SEROLOGICAS EN EL PACIENTE NN 4

\begin{tabular}{|c|c|c|c|c|c|c|c|c|}
\hline \multirow{2}{*}{$\begin{array}{c}\text { No DE } \\
\text { LABORATORIO }\end{array}$} & DIA DE & \multirow{2}{*}{ A. V. } & \multirow{2}{*}{ N.T. } & \multicolumn{4}{|c|}{ H.I. } & F.C. \\
\cline { 4 - 9 } & & & & F.A & $D_{1}$ & $D_{2}$ & $D_{3}$ & F.A. \\
\hline
\end{tabular}

\begin{tabular}{|c|c|c|c|c|c|c|c|c|}
\hline 337342 & $4^{\circ}$ & + & 0 & 0 & 0 & 0 & 0 & $*$ \\
\hline 337348 & $7^{\circ}$ & 0 & + & 0 & 0 & 0 & 0 & 0 \\
\hline 337357 & $15^{\circ}$ & 0 & + & $1 / 80$ & $1 / 40$ & $1 / 40$ & $1 / 20$ & $8 / 8$ \\
\hline
\end{tabular}

* No se realizó
0 Negativo
+ Positivo
A.V. Aislamiento de virus

N.T Neutralización

H. I Inhibición de hemaglutinación

F.C. Fijoción de Complemento

En la región de Valledupar es imposible conocer la tasa de mortalidad específica, pues allí, con excepción de uno, todos los casos que llegaron al conocimiento nuestro, fueron letales.

De los 14 casos de la región de Santa Marta, nueve fueron letales; igualmente allí se desconoce el total de infecciones para poder establecer la tasa de mortalidad específica.

\section{DISTRIBUCION GEOGRAFICA}

En la Fig. No. 7 muestra las localidades en donde se infectaron los 20 casos humanos comprobados, seis en la región vecina de Valledupar y 14 en zonas más o menos vecinas a la ciudad de Santa Marta. 


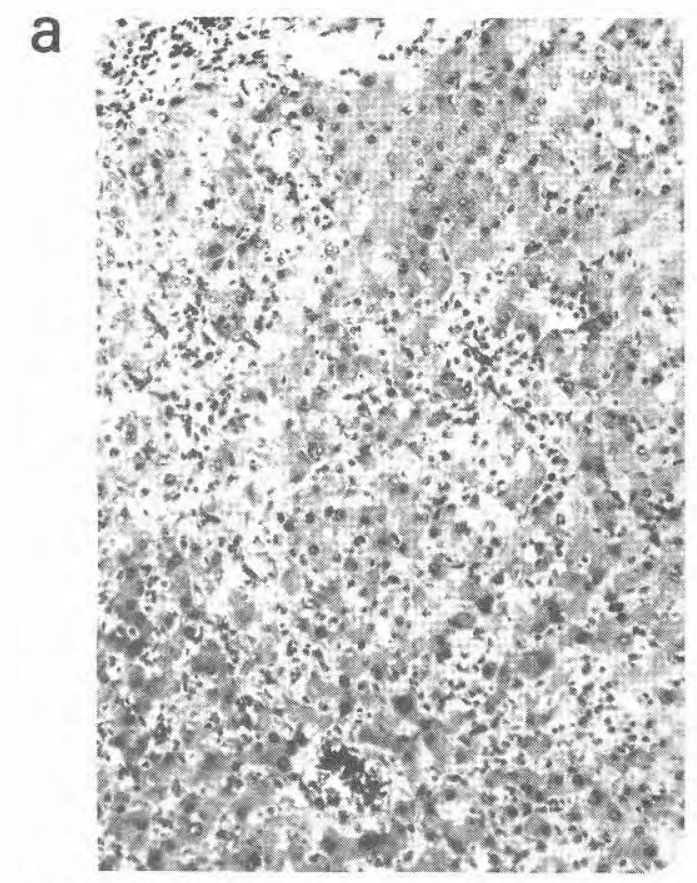

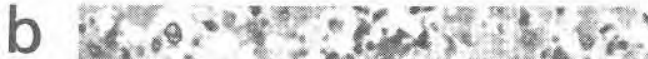

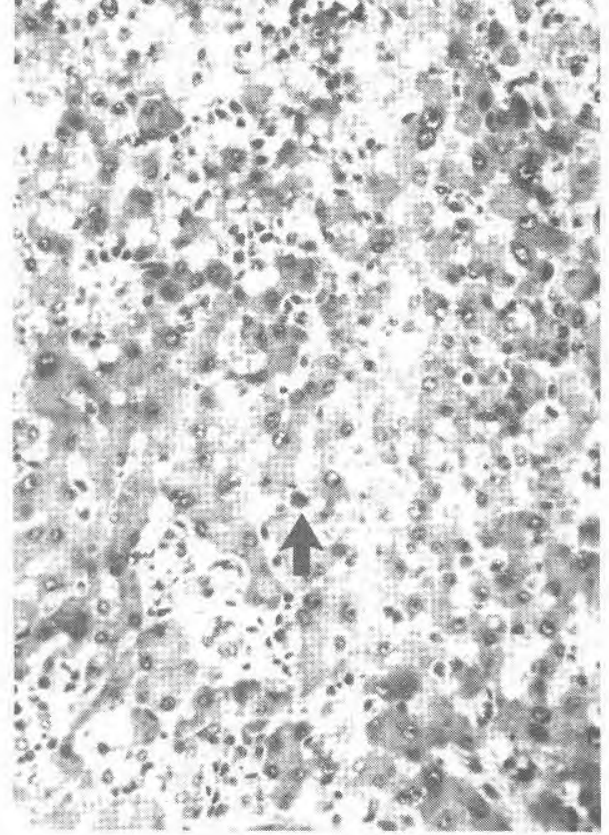

C

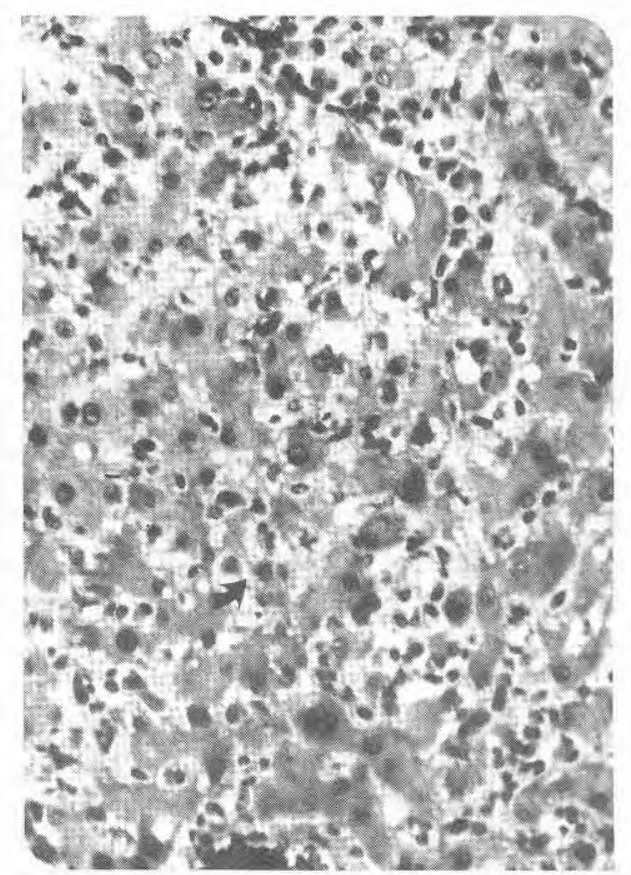

d

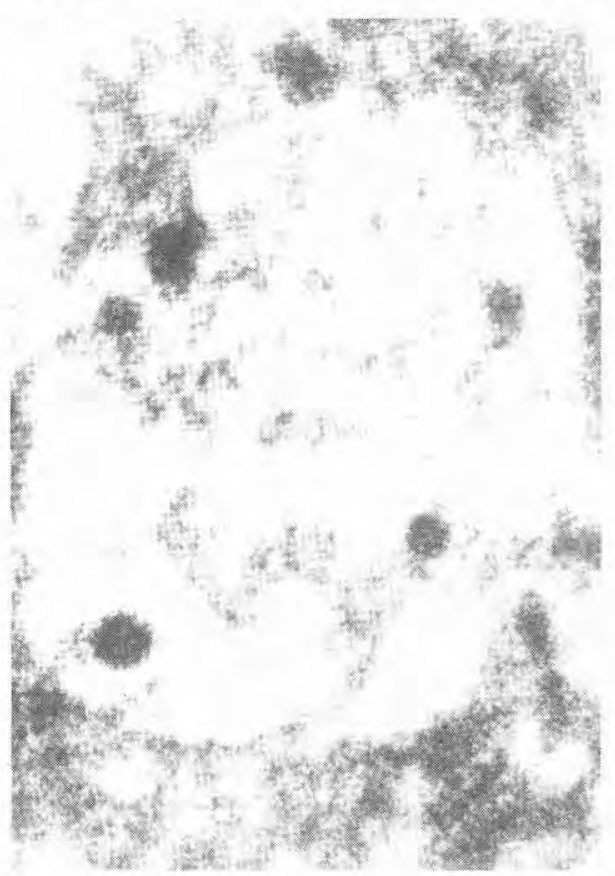

Fig. 5. a. Despoblación de células parenquimatosas predominante en la zona media del lobulillo. HE I00x $(56313)$. b. Infiltración histio linfocitaria que reemplaza a las células parenquimatosas desaparecidas; la fle. cha señala un único Cuerpo de Councilman. HE $260 \times$ (56313). c. Infiltración histio-linfocitaria con macró. fagos llenos de pigmento biliar; la flecha muestra vacuolización en uno de ellos (Cuerpos de Villela) $H E$ 40O $x$ (56313). d. Hígado de un caso fatal de la Sierra Nevada (56255). Espécimen tomado I5 minutos después del deceso y procesada para ultraestructura; dentro de una vacuola en una célula parenquimatosa se ven estructuras de aproximadamente $35 \mathrm{~nm}$ con caracteristicas, sugestivas de corresponder a virus de la fiebre amarilla. 

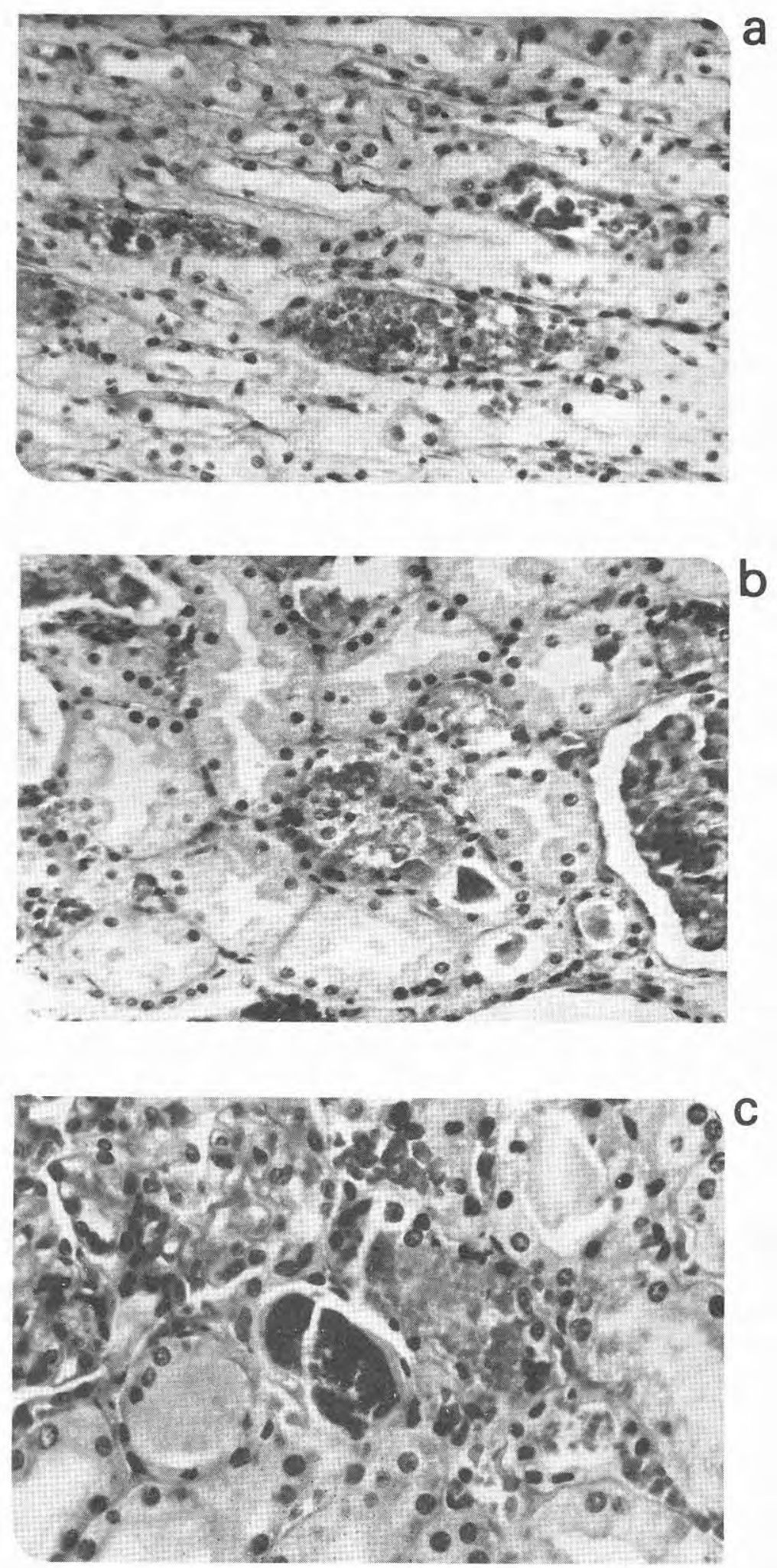

FIGURA 6.

a. Túbulos medulares con necrosis epitelial y células descamadas entre un cilindro de hemoglobina HE 250 $x(56275)$.

b. Túbulo proximal con necrosis del epitelio y cilindro de hemoglobina. HE $250 \quad x$ (56255).

c. Subyacente a un túbulo proximal con necrosis y cilindro de hem oglo. bina se observa otro con aplanamien. to epitelial ocupado por cilindro cal. cáreo. HE 400 x (56235). 


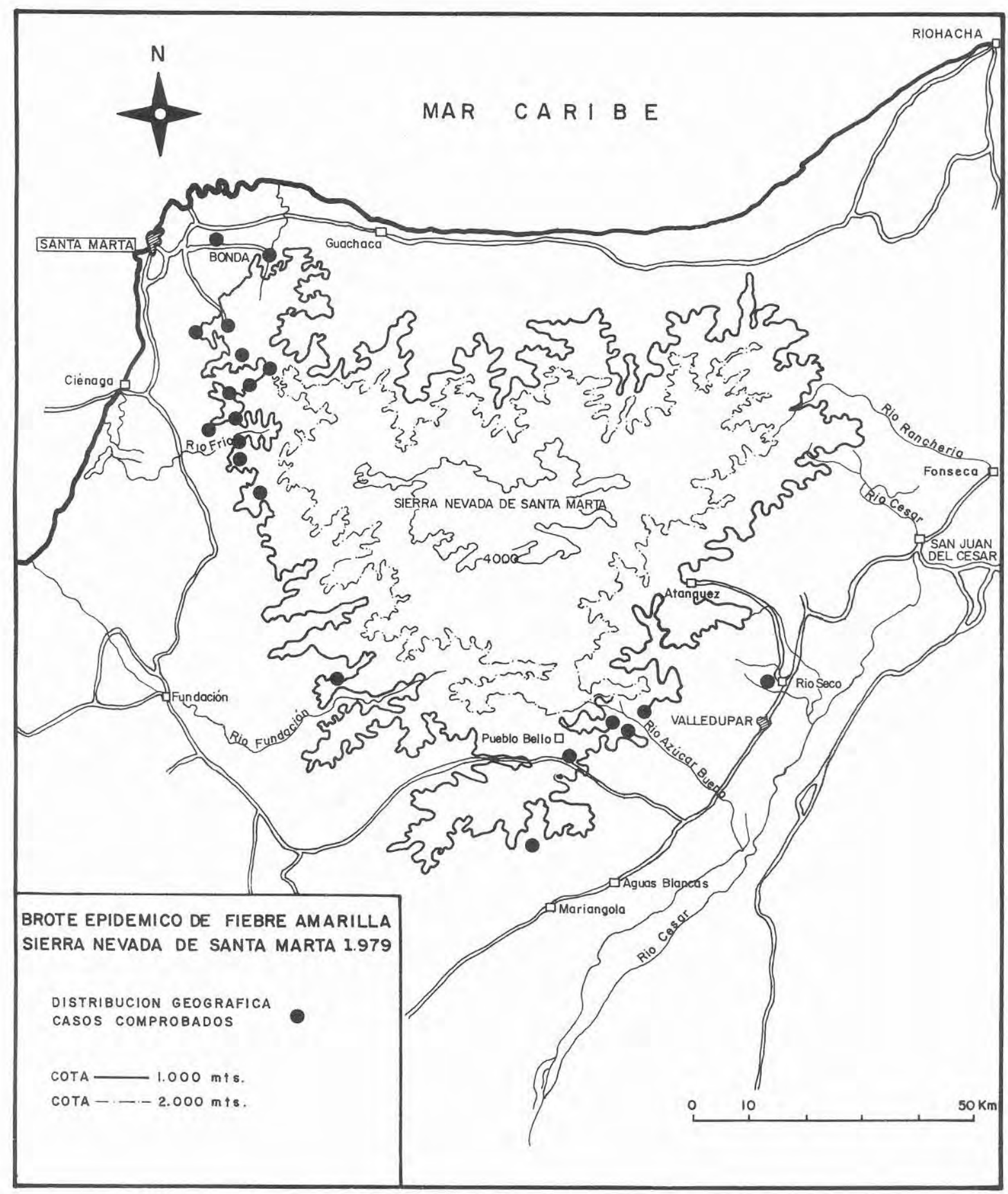




\section{DATOS EPIDEMIOLOGICOS VARIOS}

En cuanto al ser humano se refiere, los 20 casos comprobados presentaron las características epidemiológicas de la fiebre amarilla selvática: todos los casos pertenecían al sexo masculino y su distribución por edades fue la siguiente: un niño de 8 años, 12 casos entre 15 y 29 años, 6 de 30 a 45 años y un caso de 53 años. En la Figura No. 5 se resume gráficamente esta distribución. Todos eran agricultores con excepción del niño, el cual sin embargo, solía acompañar a su padre cuando éste se dedicaba a sus labores agrícolas. De uno de los casos: (No. 2) no se sabe con exactitud en dónde se infectó, según se explicó antes: si en Río Seco, población infestada con Aedes aegypti, en donde dormía o en una finca cercana, a 2 kilómetros de distancia, donde hay Haemagogus janthinomys. Diecinueve de los casos adquirieron la infección en regiones rurales que, si bien están dedicadas esencialmente a cultivos diversos, aún conservan algunas áreas boscosas de pequeña extensión, en particular a lo largo de los ríos. De esos 19 casos, 8 trabajaban especialmente en cafetales, 3 en cultivos de marihuana, 2 en plataneras y 1 en una tomatera; no se conocen con precisión los tipos de cultivo a los cuales se dedicaban los cinco agricultores restantes. Por lo menos dos de los 20 casos comprobados correspondían a gentes relativamente recién llegadas al lugar donde se infectaron y provenientes de regiones donde no se han registrado casos de fiebre amarilla. Los demás eran residentes de la zona donde se desarrolló la epidemia.

\section{ESTUDIO SOBRE MONOS}

Los estudios sobre monos de la región se limitaron a la captura de 31 ejemplares de Alouatta seniculus en bosques de Mariangola y Río Seco, vecinos a Valledupar, y al estudio serológico posterior. En 4 de los monos se encontró evidencia de infección amarílica previa, a juzgar por la prueba de neutralización positiva para fiebre amarilla que presentaron.

Durante un día uno de nosotros exploró en busca de monos, algunos bosquecillos de la región de Río Seco, donde presumiblemente se infectaron dos de los casos humanos fatales. Durante esta breve excursión se encontraron cuatro esqueletos de Alouatta. (Fig. 8). Este hallazgo indica sin duda una

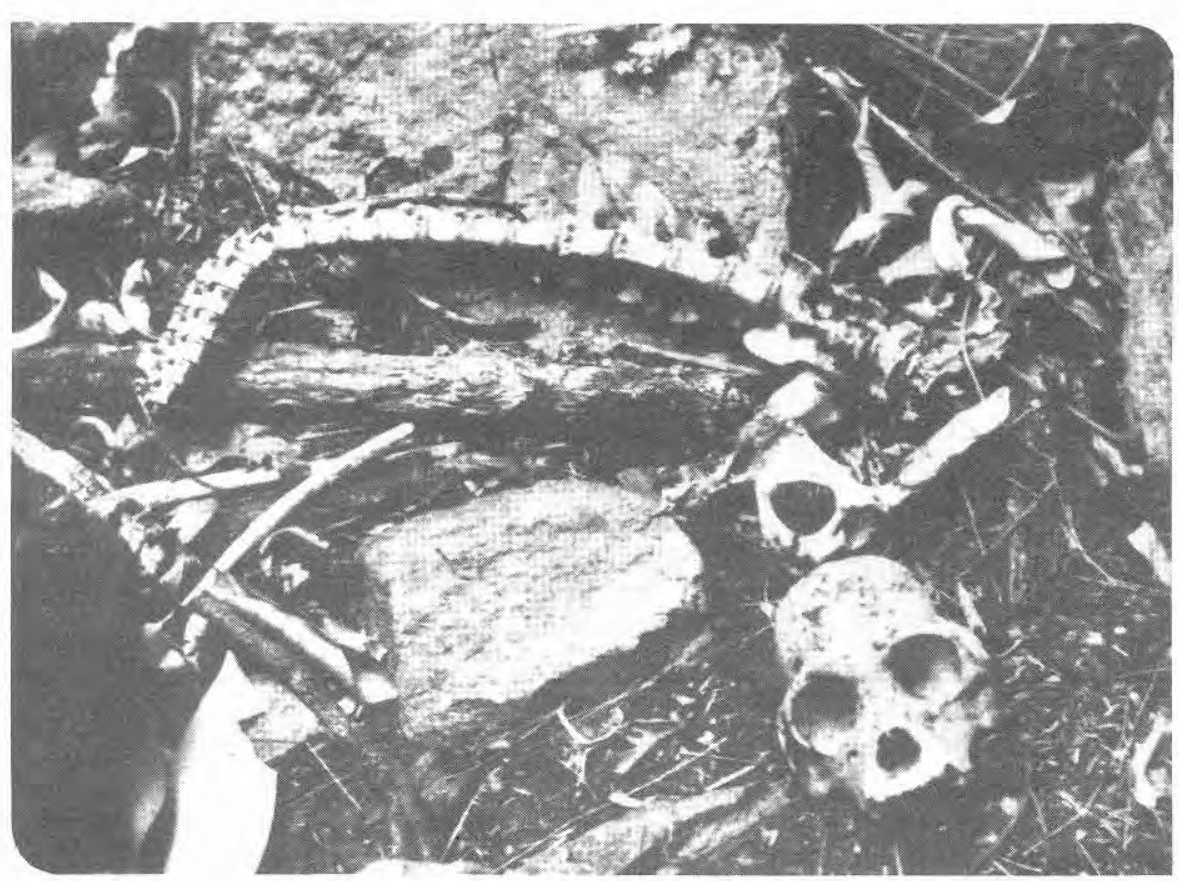

Fig. 8. Osamentas de Alouatta seniculus $h a$ llados en la región de Mariangola. 
epizootia reciente de magnitud considerable. En efecto, cuando con base en los datos sobre mortalidad de monos que suministran los habitantes de una región, el investigador científico hace una exploración de la misma para buscar cadáveres o esqueletos, lo común es no encontrarlos. Tal vez puede deberse este fenómeno a que con frecuencia el investigador realiza su estudio mucho tiempo después de la observación hecha por los campesinos o no va exactamente a los mismos sitios donde estos encontraron alguno 0 algunos monos muertos.

La presencia de anticuerpos contra la fiebre amarilla en $12 \%$ de los monos y la comprobación de una epizootia en los primates, no solamente muestra una vez más cómo estos animales intervienen en el ciclo silvestre de la enfermedad sino indican que la región o había sido visitada por la fiebre amarilla solamente mucho tiempo atrás o nunca antes había estado expuesta a tal enfermedad.

En Colombia, en las zonas donde se presenta la fiebre amarilla más o menos de manera permanente, tal como ocurre en el Valle del Magdalena Medio, o en forma periódica, como en el Pie de Monte de los Llanos Orientales, lo común es que no hay historia de monos muertos y que la proporción de monos inmunes sea alta.

\section{VECTORES}

Para estudiar los vectores se hicieron capturas diurnas de mosquitos generalmente entre 10 a.m. y 4 p.m., usando cebo humano y mariposero y colocándolos inmediatamente entre hielo seco. Las capturas se realizaron en dos tipos de zonas ecológicamente distintas. (8). El primero correspondía a zonas estrechas de bosque húmedo tropical de galería, primario o secundario, distribuídas en distintas regiones de la Sierra en las cuales presumiblemente se infectaron todos los casos comprobados, con excepción de uno. El segundo tipo correspondía exclusivamente a la finca El Cotoprix, cercana a Río Seco, según se describió antes, lugar donde hay bosque seco tropical con vegetación raquítica y escasa. (Fig. 2).
Las capturas en los bosques de galería se hicieron en dos épocas diferentes: la primera entre agosto 6 y septiembre 13, al comienzo de la estación lluviosa, en bosques tanto vecinos a Valledupar como cercanos a Santa Marta (El Campano); la segunda, un mes después de terminadas las lluvias en lugares cercanos a Valledupar. Los mosquitos encontrados, así como su densidad se indican en las Tablas 5 y 6.

TABLA No, 5

BOSQUES DE GALERIA DE LA SIERRA NEVADA DE SANTA MARTA CAPTURAS HECHAS AL COMIENZO DE LA ESTACION LLUVIOSA Y

EXPRESADAS EN NUMERO DE MOSQUITOS POR HORA-HOMBRE

\begin{tabular}{|c|c|c|c|c|}
\hline Haemagogus janthinomys & 0 & 0,33 & 0 & 0.78 \\
\hline Haemagogus equinus & 0.09 & 0 & 0 & 0.68 \\
\hline Aedes leucocelaenus & 0 & 0.09 & 0 & 0 \\
\hline Aedes terrens & 0 & 0.90 & 0.05 & 0.31 \\
\hline Aedes (Soperia) sp. & 0 & 0.04 & 0 & 0 \\
\hline Aedes scapularis & 0 & 0.19 & 0 & 0 \\
\hline Aedes whitmorei & 0 & 7. 24 & 0 & 0.89 \\
\hline Sabethes chloropterus & 0 & 1,62 & 0 & 1.10 \\
\hline Sobethes belisarioi & 0 & 0.19 & o & 0.37 \\
\hline Sabethes quosicyaneus & 0 & 0 & 0 & 0.05 \\
\hline Psorophora albipes & 0 & 0.43 & 0 & 0.15 \\
\hline Psorophora cingulata & 0 & 0.04 & 0 & 0.05 \\
\hline Limatus durhami & 0 & 0 & 0 & 0.10 \\
\hline Limatus asulleptus & 0 & 0.04 & 0 & 0.10 \\
\hline Trichoprosopon longipes & 0 & 0.52 & 0 & 0 \\
\hline Trichoprosopon leucopus & 0 & 0 & 0 & 0.05 \\
\hline Culex (Culex) spp. & 0 & 0.90 & 0 & 1.84 \\
\hline Wyeomyia (Wyeomyia) spp & 0 & 2.09 & 0 & 0.79 \\
\hline
\end{tabular}

* Metros sobre el nivel del suelo

Tiempo de coptura de $0-2 \mathrm{~m}, 21 \mathrm{~h}$

de $4-7 \mathrm{~m}, 19 \mathrm{~h}$

No parece haber diferencia significativa entre el número de Haemagogus capturados a nivel del suelo y a cierta altura en los árboles, pero es necesario aclarar que las capturas en lo alto se realizaron a alturas no mayores de 7 metros por encima del nivel del suelo.

De los varios sitios de bosque de galería donde aparentemente se infectaron los casos de fiebre amarilla, se exploraron 7 . En cinco 
de ellos se comprobó la presencia de Haemagogus janthinomys durante el curso de la epidemia en agosto; en uno (Buenos Aires), estudiado apenas durante 45 minutos/hombre, no se encontró la especie aludida pero sí se comprobó su presencia en una visita posterior, cuatro meses más tarde, (ver Tabla 6) en el sitio restante, La Victoria, visitado tan solo una vez en agosto 15 , no se encontró $H$. janthinomys, aunque sí Sabethes chloropterus.

\section{TABLA No. G}

BOSQUES DE GALERIA DE LA SIERRA NEVADA DE SANTA MARTA: CAPTURAS HECHAS UN MES DESPUES DE TERMINADA LA ESTACION LLUVIOSA Y EXPRESADA EN NUMERO DE MOSQUITOS POR HORA-HOMBRE

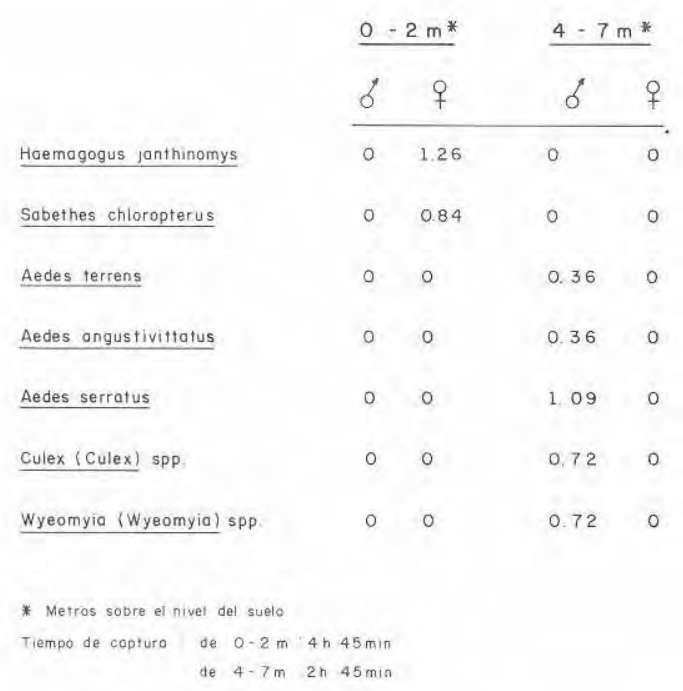

En la finca de bosque seco denominada $\mathrm{El}$ Cotoprix, una primera visita en agosto 17 de 1979 , esto es, tres semanas después de la muerte del paciente A. M. que trabajó allí, reveló tan solo una hembra de Sabethes belisarioi, encontrada durante una captura de 4 horas/hombre. En el curso de esta visita, además, se colectó material del fondo de 2 huecos de árboles, del cual, una vez inundado con agua en el laboratorio, emergieron larvas que progresaron a adultos así: 16 de Aedes terrens, 9 de Haemagogus equinus y uno de Haemagogus celeste. En el mismo lugar se hicieron dos series de captura posteriores, una durante la estación de lluvias entre septiembre 11 y octubre 11 de 1979 y otra entre diciembre 14 y diciembre 19, un mes después del término de la estación lluviosa. Los resultados, presentados en las Tablas 7 y 8 muestran presencia de $H$. janthinomys y abundancia de $H$. equinus.

Con 745 mosquitos se hicieron 192 mezclas por especie y localidad para hacer intento de aislamiento de virus. Solo uno, constituído por $H$. janthinomys capturado en Villa Rosa en agosto, dió resultado positivo, habiéndose aislado virus de fiebre amarilla.

TABLA No, 7

BOSQUE SECO DE LA FINCA COTOPRIX CAPTURAS HECHAS DURANTE LA ESTACION LLUVIOSA Y EXPRESADA EN NUMERO DE MOSQUITOS POR HORA-HOMBRE

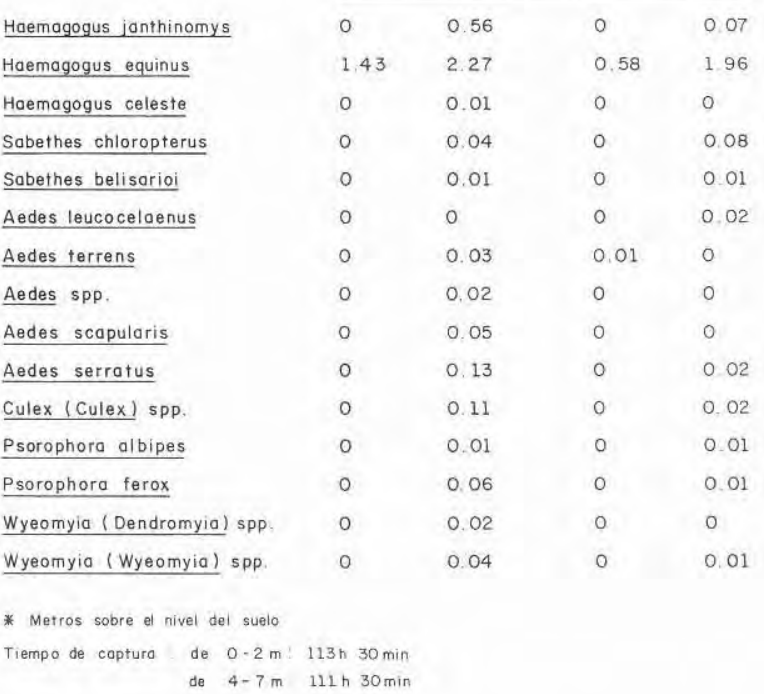

En resumen, en las áreas epidémicas se encontraron las siguientes especies de mosquitos considerados como transmisores reales o potenciales de fiebre amarilla, en orden de frecuencia, así: 
H. equinus:

$$
512 \text { hembras y }
$$$$
231 \text { machos }
$$

H. janthinomys:

126 hembras

S. chloropterus:

73 hembras

A. terrens:

29 hembras

\section{A. leucocelaenus: \\ 4 hembras \\ H. celeste: \\ 1 hembra}

Es interesante anotar la presencia de $H$. celeste, buen vector en Venezuela y que en el área rural penetra a las habitaciones humanas (9). Tiene también importancia señalar el haber encontrado el $H$. janthinomys a alturas de 1.400 metros sobre el nivel del mar en El Campano, en la vertiente nor-occidental de la Sierra, cercana a la ciudad de Santa Marta, lo cual indica que este mosquito tiene una distribución con altura mayor de la que se le conocía antes y que era de 0 a 926 metros sobre el nivel del mar.

TABLA No. 8

BOSQUE SECO DE LA FINCA EL COTOPRIX

CAPTURAS HECHAS DESPUES DE TERMINADA LA ESTACION LLUVIOSA Y EXPRESADA EN NUMERO DE MOSQUITOS POR HORA-HOMBRE

\begin{tabular}{|c|c|c|c|c|}
\hline & \multicolumn{2}{|c|}{$\underline{0-2 m^{*}}$} & \multicolumn{2}{|c|}{$\underline{4-7 m^{*}}$} \\
\hline & $\delta$ & q & $\delta$ & $q$ \\
\hline Haemagogus fanthinomys & 0 & 1.37 & 0 & 1.00 \\
\hline Haemagogus equirus & 0.05 & 1,00 & 0 & 1.50 \\
\hline Sabethes belisarioi & 0 & 0.05 & 0 & 0 \\
\hline Aedes scapularis & 0 & 0.22 & 0 & 0 \\
\hline Culex (Culex) sp & 0 & 005 & 0 & 0 \\
\hline Mansonia titillans & 0 & 0.05 & 0 & 0 \\
\hline Wyeomyia (Wyeomyia) Spp & 0 & 0.11 & 0 & 0 \\
\hline
\end{tabular}

* Metros sobre el nivel del suelo

Tiempo de captura de $0-2 \mathrm{~m} \quad 18 \mathrm{~h} 15 \mathrm{~min}$ de $4-7 \mathrm{~m} \quad 2 \mathrm{~h}$

\section{ORIGEN DE LA EPIDEMIA}

No es fácil establecer la ruta que siguió el virus hasta invadir la Sierra. Tan solo se puede especular que debió llegar allí como resultado de una extensión de la actividad viral de algún foco enzoótico. En el Valle del Magdalena el foco enzoótico más cercano a Valledupar con actividad viral permanente o casi permanente es San Vicente de Chucurí se comprobó la última muerte por fiebre amarilla en julio de 1979. De haberse originado allí el virus, lo probable es que en migración hacia el norte hubiera dejado víctimas reconocibles ya que habría recorrido una zona, la cual, si bien ya muy deforestada, cuenta con población humana abundante y susceptible. Otro foco que mostró actividad viral recientemente fue la región del Tarra, donde después de un silencio de 25 años se presentó una epidemia seria a mediados de 1978. El Río Tarra nace en la vertiente oriental de la Cordillera Oriental y hace parte de la cuenca del Río Catatumbo, afluente del Lago de Maracaibo. No es imposible que el virus del Tarra hubiera encontrado un camino por encima de la Cordillera Oriental aprovechando algunos lugares en que la altura de ésta es de 1.300 a 1.400 metros y siguiendo hacia el oeste se hubiera extendido entonces por los bosques de la vertiente occidental de la cordillera, hasta llegar por el norte a Valledupar donde se manifestó en febrero de 1979 y hacia el sur en Río de Оro donde se le comprobó en julio del mismo año.

La ruta del virus hasta el Catatumbo, zona que no se considera como enzoótica permanente, sino a donde el virus llega de tarde en tarde, parece ser, según Boshell (10) siguiendo los bosques del Río Lobaterita, conectados con los del pie de monte de los llanos venezolanos. Las epidemias del Catatumbo no serían pues sino extensiones ocasionales de las ondas periódicas que se presentan en la periferia de la gran cuenca OrinocoAmazónica, opinión ésta que no es compartida por Gast (1).

\section{CONTROL DE LA EMERGENCIA}

El control de la emergencia estuvo a cargo del Servicio de Erradicación de la Malaria, 
dependencia del Ministerio de Salud que tiene a su cargo este tipo de actividades y que hizo una publicación al respecto (11).

El control comprendió esencialmente vacunación masiva y aplicación de insecticidas para abatir la población de adultos de Aedes aegypti. Una vez comprobado el segundo caso de fiebre amarilla, el fallecido en julio 9 de 1979, se iniciaron las acciones de vacunación. Entre el 2 y el 8 de agosto se vacunaron 38.000 personas en la zona rural $\mathrm{y}$ en pequeños poblados vecinos a Valledupar. A continuación, entre el 9 y el 12 de agosto se vacunó la población del área urbana de Valledupar: 117.000 personas en total. En las semanas y meses siguientes se continuó la vacunación pero a un ritmo menos intenso. En total, hasta fines de diciembre de 1979 se inmunizó con vacuna de 17D a 620.259 personas; 471.779 en núcleos urbanos y 148.480 en zonas rurales.

La lucha contra los adultos de A. aegypti se inició también en los primeros días de agosto y consistió en la aplicación de Malathion en volumen ultrabajo en Valledupar y en otras localidades urbanas de la zona con infestaciones altas por el mosquito. En la ciudad de Valledupar se hicieron 3 ciclos con intervalos de 5 días, los cuales determinaron un descenso no cuantificado de la población de Aedes, que se estimaba inicialmente en un $43 \%$.

\section{SUMMARY}

During 1979 an epidemic of sylvan nellow fever was observed in Colombia, in the lower slopes of the Sierra Nevada the Santa Marta, where the disease had not been registred before. The cases occurred in the vicinity of the cities of Velledupar and Santa Marta, at that time infested with Aedes aegypti. Twenty cases were demonstrated by histopathological examination of the liver or by virus isolation. Thirty six additional cases were clinically diagnosed. In the first group there were 14 fatalities; in the second 13. In the urban localities in the area emergency control measures against $A$. aegypti and vaccination were carried out. No urban cases of the disease were observed.
Cases were infected in narrow gallery forests and in coffee groves, where previous and concurrent mortality in monkeys (Alouatta seniculus), was observed. The entomological survey showed in the region the presence of 3 species of Haemagogus, $H$. janthinomys among them. Of 745 captured mosquitoes divided into 192 pools, only one, composed by $\mathrm{H}$. janthinomys was positive for jellow fever virus.

The aforementioned epidemic constitutes an example of the power of invasion of yellow fever virus to new rural "habitats" creating at the same time a serious threat to neighboring cities infested with $A$. aegypti, because of the risk of urbanization of the virus, a situation which demands immediate action to abate the mosquitoe and to vaccinate the human population.

\section{BIBLIOGRAFIA}

1. Gast-Galvis A. Historia de la Fiebre Amarilla en Colombia (en prensa).

2. Gast-Galvis A. y Col. Natural Yellow Fever Infection in a Monkey. Ann Soc. Biol, Bogotá, 1954; 6 (3); 147

3. Aguilera A. y Col. Hepatitis Fulminante Epidémica de la Sierra Nevada de Santa Marta. 1. Estudio de un Brote en la Localidad de Julio Zawady, Ciénaga, Magdalena, Colom. bia. Biomédica. 1981; 1 (4)

4. Buitrago G y Col. Hepatitis Fulminante Epidémica de la Sierra Nevada de Santa Marta. 2. Revisión Epidemiolo gica, Clínica e Histopatológica. (en elaboración).

5. Strano AJ y Col. Manual sobre la Fiebre Amarilla y su Diagnóstico Diferencial Histopatológico. Publicación Cientifica de la O.P.S. 1975; No. 299

6. Villela E. Histology of Human Yellow Fever when Death is Delayed. Arch Path. 1941; 31: 665.

7. Meadows R. Renal Histopathology. 1973. Oxford Medical Publications. pp 118-122. Oxford Universify Press.

8. Morales-Alarcón A. Distribución Geográfica Horizontal y Vertical, de Haemagogus (Diptera, Culicidae) de Colom bia. Rev. Acad. Colombiana Ciencias exactas Fisicas y Naturales. $1968 ; 13(50): 267$.

9. Osorno E y Morales A. Informe sobre Investigaciones de Haemagogus y otros Artrópodos Hematófagos en Direren tes Areas de Venezuela y sobre Adiestramiento de Personal. Washington, O.S.P. Mimeografiado. 1972.

10. Boshell-Manrique J. The Yellow Fever Reservoir of the Orinoco-Amazon Basin. Am J Trop Med. 1948; $28: 457$

11. Campos G y Col. Fiebre Amarilla en la Sierra Nevada de Santa Marta. Estudio y Control de una Epidemia. Impren ta "offset" S.E.M. 1980 